\title{
KRAUJAVIMO RIZIKOS VEIKSNIŲ PASISKIRSTYMAS TARP PACIENTŲ, KURIEMS İVYKO SIMPTOMINIS VITAMINO K ANTAGONISTŲ PERDOZAVIMAS
}

\author{
Pranas Šerpytis, Sigita Glaveckaitė, Mindaugas Lizaitis \\ Vilniaus universiteto Medicinos fakulteto Širdies ir kraujagysliu ligu klinika, \\ Skubios medicinos centras
}

Raktažodžiai: vitamino K antagonistai, varfarino perdozavimas, mirtinas kraujavimas, kraujavimo rizikos veiksniai.

\section{Santrauka}

Tyrimo tikslas. Nustatyti, kokie papildomi rizikos veiksniai be varfarino perdozavimo būdingi pacientams, kuriems perdozavimas pasireiškia simptomiškai - ivyksta kraujavimas, didysis kraujavimas arba kraujavimas, kuris buvo tiesioginè ar predisponuojanti mirties priežastis. Metodika. Atlikta retrospektyvine pacientų, perdozavusių vitamino $\mathrm{K}$ antagonistus ir gydytų VUL Santaros klinikose nuo 2010-01-01 iki 2016-10-31, analizè. Varfarino perdozavimu laikytas TNS padidejimas $>3$, varfarino vartojimo fone, nesant kitų tokio padidejjimo priežasčių ir esant nustatytam varfarino perdozavimui paciento galutinejje klinikinejje diagnozejje arba nesant TNS $>3$, tačiau esant kraujavimo reiškiniams varfarino vartojimo fone, kai nèra kitų kraujavimo priežasčių. Tyrimo metu lyginti demografiniai rodikliai bei kraujavimo rizikos veiksniai tarp kraujavusių ir nekraujavusių pacientų. Rezultatai. Tirti 518 pacientų, 253 (48,8\%) vyrai, 265 $(51,2 \%)$ moterys, vidutinis amžius $73,2 \pm 11,2$ metai. Kraujavo 298 (57,5\%) pacientai, 149 (50\%) moterys, amžiaus vidurkis $72,3 \pm 11,7$ metai. Kraujavusiems anamnezejje dažniau pasitaikydavo kraujavimas iš virškinimo trakto: $16(5,4 \%)$ vs. $3(1,4 \%)(p=0,017)$. Didysis kraujavimas pasireiške 162 pacientams, vidutinis amžius $72,8 \pm 11,8$ metai, 88 (54,3\%) moterys. Šiai grupei taip pat būdingesnis kraujavimas iš virškinimo trakto anamnezejje - $10(6,2 \%)$ vs. $9(2,5 \%)$ $(\mathrm{p}=0,04)$. Mire $56(10,8 \%)$ pacientai, vidutinis amžius 74,8 111,2 metai, 27 (48,2\%) moterys. Mirusieji dažniau sirgo inkstų ligomis (kreatininas viršijo $200 \mu \mathrm{mol} / 1)-17(30,4 \%)$ vs. $64(13,9 \%)(\mathrm{p}=0,001)$. Išvados. Pacientams, po varfarino perdozavimo patyru- siems kraujavimą arba didiji kraujavimą, būdingesnis kraujavimas iš virškinimo trakto anamnezèje. 9,4\% visų îvykusių kraujavimų buvo mirtini, tarp pacientų, kurie mirè, dažniau pasitaikè kreatinino padidejjimas daugiau kaip $200 \mu \mathrm{mol} / \mathrm{l}$ ir inkstų ligos. Ivykus varfarino perdozavimui, pastarieji veiksniai galètų būti prognostiniai, jog perdozavimas taps simptominis, todèl ateityje reikia detaliau šiuos veiksnius ištirti.

\section{Ivadas}

Vitamino K antagonistas varfarinas dažniausiai vartojamas antikoaguliantas Lietuvoje. Be to, varfarino vartojimas Lietuvoje vis didejja: 2013 metais šio vaisto santykinis suvartojimas buvo 8,77/1000 gyventojų/per dieną, o 2015 metais - 9,89/1000 gyventoju/per dieną, taigi santykinai suvartojimas išaugo $12,7 \%$. Tai taip pat reiškia, kad beveik vienas iš šimto Lietuvos gyventojų kasdien vartoja varfariną (1). Antikoaguliacinis gydymas varfarinu naudojamas giliujų venų trombozès (GVT) ir/ar plaučių arterijos tromboembolijos (PATE) profilaktikai/gydymui, taip pat insulto profilaktikai esant prieširdžių virpèjimui (PV), esant implantuotiems mechaniniams širdies protezams $(2,3)$. Antikoaguliacinis gydymas efektyviai mažina trombozių ir galvos smegenų išeminio insulto dažnị ir padeda išvengti sunkių su šiomis būklèmis susijusių komplikacijų (4). Tačiau dèl ilgalaikio, neretai visą likusi gyvenimą trunkančio vaisto vartojimo (3), ịvairių tyrimų duomenimis, nuo 3,9\% iki 11,6\% pacientų pasireiškia nepageidaujama gydymo varfarinu reakcija - kraujavimas $(5,6)$. Ivairių tyrimų duomenimis, pasikartojančios tromboembolijos rizika persirgus PATE ar GVT gali siekti 27\%, tuo tarpu didžiojo kraujavimo rizika vartojant antikoaguliacini gydymą $-3,7 \%$ per metus, taigi, akivaizdu, jog esant mažai kraujavimo rizikai trombozių prevencijos nauda atperka galimo kraujavimo pavojų (7). Kad būtų galima tinkamai pasverti potencialią antikoaguliacinio gydymo naudą ir žalą, svarbu žinoti kraujavimo tikimybę konkrečiam pacientui. 
Darbo tikslas: nustatyti, kokie papildomi rizikos veiksniai be varfarino perdozavimo būdingi pacientams, kuriems perdozavimas pasireiškia simptomiškai - ivvyksta kraujavimas, didysis kraujavimas arba kraujavimas, kuris buvo tiesioginè ar predisponuojanti mirties priežastis.

\section{Darbo objektas ir metodika}

Tirti suaugusieji pacientai dèl vitamino $\mathrm{K}$ antagonistu (varfarino) perdozavimo gydyti Vilniaus universiteto ligoninèje Santaros klinikose (VULSK) nuo $2010 \mathrm{~m}$. sausio $1 \mathrm{~d}$. iki 2016 m. lapkričio 11 d. Varfarino perdozavimu laikytas TNS padidejimas $>3$ varfarino vartojimo fone, nesant kitu tokio padidėjimo priežasčių ir esant nustatytam varfarino perdozavimui paciento galutinèje klinikinëje diagnozeje arba nesant TNS $>3$, tačiau esant kraujavimo reiškiniams varfarino vartojimo fone, kai nėra kitų kraujavimo priežasčių. Remiantis Kuijer ir kt. 1999; Beyth ir kt. 1998; Gage ir kt. 2006 (HEMORR HAGES); Shireman ir kt. 2006; Pisters ir kt. 2010 (HAS-BLED) nustatytais kraujavimo rizikos veiksniais buvo surinkti šie duomenys apie pacientus: amžius, lytis, išgyvenamumas iki hospitalizacijos pabaigos, sergamumas arterine hipertenzija, kepenų ar inkstų ligos, anksčiau buvę išeminiai insultai ar praeinantys smegenų išemijos priepuoliai, anksčiau buvę kraujavimai iš virškinimo trakto, piktybinès ligos anamnezeje, anksčiau įvykęs miokardo infarktas, griuvimai anamnezėje, cukrinis diabetas, kreatinino maksimali nustatyta TNS reikšmė (8-12). Informacija gauta iš pacientų elektroninių ligos istorijų (ELI) duomenų bazès. Remiantis HAS-BLED skalès rekomendacijomis reikšminga kreatinino kiekio kraujyje padidejjimo riba buvo pasirinkta $200 \mu \mathrm{mol} / \mathrm{l}(8)$. Taip pat buvo analizuojama, ar buvo ịvykęs kraujavimas, jo lokalizacija. Jeigu kraujavimas pasireiškè kaip hemoraginis insultas, hemoraginis šokas, vidinis kraujavimas arba kraujavimo padariniams gydyti reikejjo perpilti du ir daugiau eritrocitų masès vienetus, kraujavimas buvo laikomas didžiuoju (13).

Gauti duomenys apdoroti IMB SPSS statistinès analizès programa. Pacientai suskirstyti ị tris poras grupių pagal tai, ar išgyveno iki hospitalizacijos pabaigos, ar buvo įvykęs kraujavimas, ar buvo įvykęs didysis kraujavimas, tuomet kiekvienu atveju palygintas rizikos veiksnių dažnis. Statistiniam reikšmingumui patikrinti naudoti chi kvadrato ir Stjudent'o (Student) $t$ testas, statistiškai reikšminga $p$ reikšme laikyta $<0,05$. Duomenų pasiskirstymas pagal normalujj skirstinį tikrintas Man'o-Vitney (Mann-Whitney) U testu.

\section{Rezultatai}

Iš viso ị tiriamają imti pagal nurodytus kriterijus pateko 518 pacientų, gydytų VULSK per beveik 7 metus. Iš šių tiriamujų 253 - vyrai, 265 - moterys, jauniausias pacientas 18 metų, vyriausias - 95 metų, amžiaus vidurkis - 73,2 $\pm 11,2$ metai, $426(82,2 \%)$ pacientai buvo 65 metų amžiaus ir

1 lentelè. Rizikos veiksnių pasiskirstymas priklausomai nuo baigčių tarp pacientų perdozavusių varfariną

\begin{tabular}{|c|c|c|c|c|c|c|c|c|c|}
\hline Rizikos veiksnys & $\begin{array}{r}\text { Išgyvenę } \\
(n=462)\end{array}$ & $\begin{array}{l}\text { Mirę } \\
(n=56)\end{array}$ & $\mathbf{p}$ & $\begin{array}{c}\text { Kraujavę } \\
(\mathrm{n}=\mathbf{2 9 8})\end{array}$ & $\begin{array}{c}\text { Nekraujavę } \\
(n=220)\end{array}$ & $\mathbf{p}$ & $\begin{array}{c}\text { Su didžiuoju } \\
\text { kraujavimu } \\
(n=162)\end{array}$ & $\begin{array}{c}\text { Be didžiojo } \\
\text { kraujavimo } \\
(n=356)\end{array}$ & $\mathbf{p}$ \\
\hline Moteriška lytis, \% & 51,5 & 48,2 & 0,64 & 50 & 52,7 & 0,539 & 51,9 & 50,8 & 0,545 \\
\hline $\begin{array}{l}\text { Amžius metais, vidurkis } \\
\text { (SD) }\end{array}$ & $73(11,2)$ & $74,8(11,2)$ & 0,252 & $\begin{array}{c}72,3 \\
(11,7)\end{array}$ & $74,4(10,4)$ & 0,035 & $72,8(11,8)$ & $73,4(11)$ & 0,612 \\
\hline Amžius >65metai, $\%$ & 80,1 & 83,9 & 0,493 & 77,9 & 84,1 & 0,076 & 79 & 81,2 & 0,845 \\
\hline Amžius >75metai, \% & 48,7 & 53,6 & 0,491 & 46,3 & 53,2 & 0,122 & 47,5 & 50 & 0,882 \\
\hline PSIP, $\%$ & 7,1 & 8,9 & 0,628 & 7 & 7,7 & 0,769 & 4,3 & 8,7 & 0,076 \\
\hline Insultas, \% & 17,3 & 21,4 & 0,446 & 19,5 & 15,5 & 0,238 & 21 & 16,3 & 0,195 \\
\hline MI, \% & 21,9 & 21,4 & 0,94 & 19,8 & 24,5 & 0,196 & 19,8 & 22,8 & 0,443 \\
\hline Arterinè hipertenzija, \% & 82 & 60,7 & $<0,001$ & 78,5 & 81,4 & 0,47 & 74,7 & 82 & 0,129 \\
\hline $\mathrm{CD}, \%$ & 22,7 & 12,5 & 0,079 & 21,5 & 21,8 & 0,926 & 22,2 & 21,3 & 0,823 \\
\hline Inkstų liga, \% & 13,9 & 30,4 & 0,001 & 15,8 & 15,5 & 0,142 & 19,1 & 14 & 0,205 \\
\hline Kepenų liga, \% & 10,2 & 17,9 & 0,083 & 12,1 & 9,5 & 0,362 & 11,1 & 11 & 0,51 \\
\hline $\begin{array}{l}\text { Ankstesnis kraujavimas } \\
\text { iš VT, \% }\end{array}$ & 3,7 & 3,6 & 0,968 & 5,4 & 1,4 & 0,017 & 6,2 & 2,5 & 0,04 \\
\hline Piktybinès ligos, \% & 19,3 & 26,8 & 0,185 & 22,8 & 16,4 & 0,067 & 19,6 & 20,2 & 0,927 \\
\hline Griuvimai, \% & 4,8 & 5,4 & 0,949 & 4,7 & 5 & & 6,8 & 3,9 & 0,243 \\
\hline $\begin{array}{l}\text { Kreatini- } \\
\text { nas }>200 \mu \mathrm{mol} / 1, \%\end{array}$ & 13,9 & 30,4 & 0,001 & 15,8 & 15,5 & 0,922 & 19,8 & 13,8 & 0,082 \\
\hline TNS vidurkis (SD) & $6,4(1,8)$ & $6,6(1,6)$ & 0,291 & $6,4(1,9)$ & $6,3(1,6)$ & 0,36 & $6,4(1,9)$ & $6,4(1,7)$ & 0,991 \\
\hline
\end{tabular}


vyresni, o 268 (51,7\%) pacientai - 75 metu ir vyresni.

Rizikos veiksnių pasiskirstymas priklausomai nuo baigčių tarp pacientų, perdozavusių varfariną, pateiktas 1 lentelèje. Iš viso kraujavimo reiškiniai pasireiškè 298 pacientams (57,5\%), o 220 (42,5\%) - nekraujavo. Rastos šios kraujavimo lokalizacijos: hematurija (kraujavimas iš šlapimo takų) $(n=40)$, kraujavimas iš virškinimo trakto $(n=145)$, vidinis kraujavimas, apimantis kraujavimą i pilvaplèves ertmę bei kraujavimą iš vidaus organų neskaitant virškinimo trakto $(n=13)$, hemoraginis šokas $(n=15)$, kuris šiuo atveju vertintas kaip masyvus kraujavimas iš bet kurios vienos ar daugiau lokalizacijų, ir hemoraginis insultas $(n=25)$. Likusios kraujavimo lokalizacijos - poodinès hematomos, atsikosėjimas krauju (nedidelis kraujavimas iš kvépavimo takų), kraujavimas iš dantenų ar iš nosies, kraujosruvos akyse ir kt. sudare likusius 70 atvejų. Dalis pacientų kraujavo iš daugiau nei vienos lokalizacijos. Lyginant kraujavusius su nekraujavusiais aptikta, jog tarp kraujavusiujų pacientų praeityje ligos anamnezėje dažniau pasitaikydavo kraujavimas iš virškinimo trakto $(p=0,017)$. Skirtumų tarp lyčių pagal kraujavimo dažnį nebuvo. Nekraujavusiujų pacientų grupeje amžiaus vidurkis buvo mažesnis, atitinkamai, $72,3 \pm 11,7$ metai kraujavusių ir 74,4 $\pm 10,4$ metai tarp nekraujavusių $(\mathrm{p}=0,035)$.

Didysis kraujavimas pasireiškè 162 pacientams. Reikšmingų skirtumų pagal amžių ir lytị lyginant su likusia imties dalimi šioje grupeje nebuvo. Taip pat kaip ir kraujavusių pacientų grupejje, pacientams su didžiuoju kraujavimu buvo būdingas dažnesnis kraujavimas iš virškinimo trakto gyvenimo anamnezeje $(\mathrm{p}=0,04)$.

Iš 518 pacientų mire 56 , tai sudarẻ $10,8 \%$ visos tiriamosios imties. 28 pacientams (50\% mirusiujų) tiesioginè mirties priežastis buvo hemoraginis insultas arba hemoraginis šokas, likusiujų - kitos priežastys, iš kurių dažniausiai pasitaikè sepsis ir onkologinès ligos. Mirtis dèl kraujavimo po varfarino perdozavimo sudare $9,4 \%$ visų įvykusių kraujavimų, taigi beveik kas dešimtas įvykęs kraujavimas buvo mirtinas. Šiek tiek dažniau mire vyrai, vyresni pacientai, tačiau šie skirtumai nebuvo reikšmingi $(p>0,05)$. Pacientai, kurie neišgyveno po varfarino perdozavimo, statistiškai reikšmingai dažniau sirgo inkstų ligomis $(\mathrm{p}=0,001)$, šị radinị taip pat patvirtina ir šioje pacientų grupejje dažniau nustatytas kreatinino padidèjimas $>200 \mu \mathrm{mol} / 1(\mathrm{p}=0,001)$. Priešingai nei tikètasi, tarp mirusių pacientų sergamumas arterine hipertenzija santykinai pasitaikè daugiau nei 20 procentų rečiau $(\mathrm{p}<0,001)$. Kiti rizikos veiksniai tarp išgyvenusių ir mirusiųjų statistiškai patikimai reikšmingai nesiskyrè, tačiau galima pastebėti tendenciją, kad dauguma tirtų rizikos veiksnių dažniau pasitaikè mirusiųu grupèje.

\section{Rezultatu aptarimas}

Ištyrus kraujavimo rizikos veiksnių paplitimą tarp varfariną perdozavusių pacientų rezultatai akivaizdžiai skiriasi nuo pateikiamų kituose tyrimuose, nagrinejjančiuose kraujavimo rizikos veiksnius. Šiuo metu viena naujausių sukurtų skalių kraujavimo rizikai ịvertinti yra Pisters ir kt. 2010 HASBLED skalè, pagal kurią kraujavimo rizikos veiksniai yra arterinè hipertenzija, kepenu/inkstų liga, insultas anamnezėje, anksčiau buvę kraujavimai, labilus TNS, amžius $>65$ metai, alkoholio ar antiagregantų vartojimas (8). Panašius rizikos veiksnius pateikia ir kiti autoriai - Gage ir kt. 2006 HEMORR ${ }_{2}$ HAGES skalè: kepenų/inkstų liga, alkoholio vartojimas, piktybinè liga, amžius $>75$ metai, trombocitopenija ar trombocitų funkcijos sumažejimas, kraujavimai anamnezèje, nekontroliuojama hipertenzija, anemija, genetiniai faktoriai (CYP2C9), padidejusi griuvimo rizika, insultas anamnezeje (9). Šiame darbe iš visų rizikos veiksnių, kurių paplitimas buvo tirtas tarp kraujavusių pacientų, reikšmingai dažnesnis buvo tik kraujavimas iš VT.

Grupuojant tiriamuosius pagal sunkesnes perdozavimo baigtis, didžiojo kraujavimo rizikos veiksniai išliko tie patys kaip ir bendro kraujavimo pasireiškimo, o nustatyti mirtinų baigčių predisponuojantys faktoriai buvo tik inkstų patologija ir kreatinino padidejimas $>200 \mu \mathrm{mol} / \mathrm{l}$. Kai kurie rezultatai buvo netgi priešingi, pvz., rečiau pasitaikanti arterinė hipertenzija tarp pacientų su letaliomis baigtimis. Pastaraji rezultatą galima paaiškinti tuo, jog neretai neišgyvenusių grupès pacientai ị ligoninę atvyksta labai sunkios būklès, todèl kai kurių gyvenimo anamnezès duomenų, tarp jų ir sergamumo arterine hipertenzija fakto, nepavyksta sužinoti, o ankstesnių įrašų apie paciento lètines ligas ELI nebūna. Netikètas buvo ir žemesnis amžiaus vidurkis nekraujavusių pacientų grupejje, tačiau, nors iš pirmo žvilgsnio toks rezultatas prieštarauja patvirtintoms kraujavimo rizikos veiksnių skalėms, kuriose amžius pripažįstamas kaip kraujavimo rizikos veiksnys, tiriamają imtị suskirsčius ị amžiaus grupes pagal kraujavimo rizikos skalėse pateiktas amžiaus ribas, atitinkamai, i jaunesnius ir vyresnius nei 65 metų amžiaus bei jaunesnius ir vyresnius nei 75 metų amžiaus pacientus, statistiškai reikšmingų skirtumų pagal kraujavimo dažni tarp grupių nebelieka, taigi priešingą amžiaus vidurkių skirtumą greičiausiai nulèmè platus tiriamosios imties amžiaus diapazonas. Vis dèlto labai svarbu pabrèžti, jog šio tyrimo rezultatai negali būti tiesiogiai lyginami su kituose tyrimuose gautais rezultatais. Anksčiau minètuose tyrimuose lyginamas rizikos veiksnių paplitimas tarp visų pacientų, vartojusių varfariną, nepriklausomai nuo to ar buvo diagnozuotas varfarino perdozavimas. Tuo tarpu šiame darbe tiriamas rizikos veiksnių pasiskirstymas tik toje vartojusios varfariną populiacijos dalyje, kurioje buvo įvykęs varfarino perdozavimas. 
Gauti rizikos faktoriai prognozuoja ne bendrą kraujavimo tikimybę pradejus vartoti varfariną, o kraujavimo tikimybę, pacientui perdozavus varfariną. Nors šiame tyrime nustatyti kraujavimo rizikos veiksniai ir neleidžia prognozuoti bendros kraujavimo rizikos populiacijoje, išskirtų rizikos faktorių reikšmė taip pat svarbi. Rizikos veiksniai, kurie išlieka statistiškai reikšmingai prognostiniai, net ir tiriant juos populiacijoje, kurioje visi pacientai turejjo padidejjusią kraujavimo riziką dèl varfarino perdozavimo, rodo stipresnę prognostinę šių veiksnių galią lyginant su kitais rizikos faktoriais. Šiuo metu daugumoje kraujavimo rizikos vertinimo skalių skirtingi veiksniai vertinami vienodu balų skaičiumi neatsižvelgiant ị skirtingą prognostinį galingumą, pvz. HASBLED skaleje visi faktoriai verti vieno balo (8), o HEMORRAGHES skalèje tik ankstesnis kraujavimas įvertintas ne vienu, o dviem balais (9). Todèl ateityje reikia detalesnio šiame tyrime išryškintų rizikos veiksnių prognostinès galios palyginimo su kitais rizikos veiksniais.

\section{Išvados}

Pacientams, po varfarino perdozavimo patyrusiems kraujavimą arba didiji kraujavimą, būdingesnis kraujavimas iš virškinimo trakto anamnezejje. 9,4\% visų įvykusių kraujavimų buvo mirtini. Tarp pacientų, kurie mirè, dažniau pasitaikè kreatinino padidejjimas $>200 \mu \mathrm{mol} / \mathrm{l}$ ir inkstų ligos. İvykus varfarino perdozavimui, šie veiksniai galètų būti prognostiniai, jog perdozavimas taps simptominis, todèl ateityje būtinas detalesnis šių veiksnių ištyrimas.

\section{Literatūra}

1. Andis Seilis, Elma Gailite, editor. Baltic Statistics on Medicines 2013-2015. 2nd edition. Riga: Dardedze hologrāfija SIA; 2016.

2. Varfarino preparato charakteristiku santrauka. Prieiga per internetą: https://vapris.vvkt.lt/vvkt-web/public/medications [žiūrèta 2017 m. gegužès 30 d.]

3. Kneeland PP, Fang MC. Current issues in patient adherence and persistence: focus on anticoagulants for the treatment and prevention of thromboembolism. Patient preference and adherence. 2010; 4:51-60.

4. Singer DE, Hughes RA, Gress DR, Sheehan MA, Oertel LB, Maraventano SW, Blewett DR, Rosner B, Kistler JP. The effect of low-dose warfarin on the risk of stroke in patients with nonrheumatic atrial fibrillation. N Engl J Med 1990; 323:1505-11. https://doi.org/10.1056/NEJM199011293232201

5. Bousser MG, Bouthier J, Büller HR. et al., for the AMADEUS Investigators. Comparison of idraparinux with vitamin $\mathrm{K}$ antagonists for prevention of thromboembolism in patients with atrial fibrillation: a randomised, open-label, non-inferiority trial. Lancet 2008; 371:315-21.

https://doi.org/10.1016/S0140-6736(08)60168-3

6. Hansen ML, Sørensen R, Clausen MT, Fog-Petersen ML,
Raunsø J, Gadsbøll N, Gislason GH, Folke F, Andersen SS, Schramm TK, Abildstrøm SZ, Poulsen HE, Køber L, Torp-Pedersen C. Risk of bleeding with single, dual, or triple therapy with warfarin, aspirin, and clopidogrel in patients with atrial fibrillation. Arch Intern Med 2010; 170 (16):1433-1441.

https://doi.org/10.1001/archinternmed.2010.271

7. Kearon C, Gent M, Hirish J. et al. Extended anticoagulation compared to placebo after three months of therapy for a first episode of idiopathic venous thromboembolism. N Engl J Med. 1999; 340:901-907

https://doi.org/10.1056/NEJM199903253401201

8. Pisters R, Lane DA, Nieuwlaat R, de Vos CB, Crijns HJGM, Lip GYH. A novel user-friendly score (HAS-BLED) to assess 1-year risk of major bleeding in patients with atrial fibrillation: the Euro Heart Survey. Chest 2010; 138(5):1093-1100. https://doi.org/10.1378/chest.10-0134

9. Gage BF, Yan Y, Milligan PE, Waterman AD, Culverhouse R, Rich MW, Radford MJ. Clinical classification schemes for predicting hemorrhage: results from the National Registry of Atrial Fibrillation (NRAF). Am Heart J 2006; 151(3):713-719. https://doi.org/10.1016/j.ahj.2005.04.017

10. Kuijer PMM, Hutten BA, Prins MH, Büller HR. Prediction of the risk of bleeding during anticoagulant treatment for venous thromboembolism. Arch Intern Med 1999; 159 (5):457-460. https://doi.org/10.1001/archinte.159.5.457

11. Beyth RJ, Quinn LM, Landefeld CS. Prospective evaluation of an index for predicting the risk of major bleeding in outpatients treated with warfarin. Am J Med 1998; 105(2):91-99. https://doi.org/10.1016/S0002-9343(98)00198-3

12. Shireman TI, Mahnken JD, Howard PA, Kresowik TF, Hou Q, Ellerbeck EF. Development of a contemporary bleeding risk model for elderly warfarin recipients. Chest 2006; 130(5):13901396.

https://doi.org/10.1378/chest.130.5.1390

13. Seet RC, Rabinstein AA, Christianson TJ, Petty GW, Brown $\mathrm{RD}$. Bleeding complications associated with warfarin treatment in ischemic stroke patients with atrial fibrillation: a populationbased cohort study. Journal of Stroke and Cerebrovascular Diseases : The Official Journal of National Stroke Association 2013; 22(4):561-569.

https://doi.org/10.1016/j.jstrokecerebrovasdis.2013.01.019

\section{RISK FACTORS DISTRIBUTION IN PATIENTS WITH SYMPTOMIC VITAMIN K ANTAGONIST OVERDOSE \\ P. Šerpytis, S. Glaveckaitė, M. Lizaitis}

Key words: vitamin $\mathrm{K}$ antagonists, warfarin overdose, lethal bleeding, bleeding risk factors.

Summary

Aim of the study. To determine risk factors for bleeding, major bleeding and death in patients with overdose of vitamin $\mathrm{K}$ antagonists. Methods. The retrospective study examined patients, who 
have overdosed vitamin K antagonists and were admitted to Vilnius university Santariškès hospital between 2010-01-01 and 201610-31. Age, sex and bleeding risk factors were compared between groups with bleeding events and without bleeding events. Results. Total of 518 patients' data were analysed, $253(48,8 \%)$ were men, $265(51,2 \%)$ women, average age was $73,2 \pm 11,2$ years old. 298 $(57,5 \%)$ had bleeding event, $149(50 \%)$ were women, average age was $72,3 \pm 11,7$ years old. Group with bleeding event were more likely to have gastrointestinal bleeding history: $16(5,4 \%)$ vs. 3 $(1,4 \%)(\mathrm{p}=0,017.162$ patients had major bleeding, average age was $72,8 \pm 11,8$ years old, $88(54,3 \%)$ were women. Major bleeding group also had more common gastrointestinal bleeding history - $10(6,2 \%)$ vs. $9(2,5 \%)(\mathrm{p}=0,04) .56(10,8 \%)$ patients died, average age was $74,8 \pm 11,2$ years old, $27(48,2 \%)$ were women . Patients with lethal outcomes had kidney disease history more of- ten (creatinine was over $200 \mu \mathrm{mol} / \mathrm{l})-17(30,4 \%)$ vs. $64(13,9 \%)$ $(\mathrm{p}=0,001)$. Conclusions. Patients who had symptomic warfarin overdose with bleeding or major bleeding were more likely to have gastrointestinal bleeding history. 9,4\% of all bleeding event were lethal. Patients who died during hospitalization and had warfarin overdose were more likely to have kidney diseases and creatinine value over $200 \mu \mathrm{mol} / \mathrm{l}$. These risk factors might be prognostic to predict if warfarin overdose will be symptomic, but futher investigation is required.

Correspondece to: mindaugas.lizaitis@gmail.com

Gauta 2017-05-30 